\title{
SCIENTIFIC SECTION
}

\section{Juvenile idiopathic arthritis (JIA): a screening study to measure class II skeletal pattern, TMJ PDS and use of systemic corticosteroids}

\author{
Nicky A. Mandall, Robin Gray, Kevin D. O'Brien \\ School of Dentistry, University of Manchester, UK \\ Eileen Baildam \\ Booth Hall Children's Hospital, Manchester, UK \\ Tatiana V. Macfarlane \\ School of Medicine and Dentistry, University of Aberdeen, UK \\ Co-authors \\ Joyce Davidson, John Sills \\ Alder Hey Children's Hospital, Liverpool, UK \\ Helen Foster \\ Newcastle University, UK \\ Janet Gardner-Medwin \\ Glasgow University, UK \\ Ann Garrahy, Declan Millett \\ Glasgow Dental Hospital and School, UK \\ Rye Mattick \\ Newcastle Dental Hospital, UK \\ Tanya Walsh, Steven Ward \\ School of Dentistry, University of Manchester, UK
}

Objective: To screen patients with oligoarticular and polyarticular forms of Juvenile Idiopathic Arthritis (JIA) to determine (i) the severity of their class II skeletal pattern; (ii) temporomandibular joint signs and symptoms and (iii) use of systemic corticosteroids.

Design: Cross-sectional screening.

Subjects and setting: Sixty-eight children with JIA aged between 9 and 16 years old who were screened at four regional treatment centres in the UK.

Method: Patients were screened clinically and radiographically for the presence of class II skeletal pattern and temporomandibular (TMJ) pain dysfunction syndrome. In addition, the JIA sub-type and history of disease activity and medication were recorded.

Main outcome measures: Class II skeletal pattern, TMJ signs and symptoms, use of systemic corticosteroids.

Results: The mean ANB values were 4.2 degrees $(\mathrm{SD}=2.9$ degrees) in the oligoarticular group and 5.1 degrees $(\mathrm{SD}=3.8$ degrees) in the polyarticular group. Just under one-third of children had a moderate or severe class II skeletal pattern and a further quarter of children had a mild class II skeletal pattern.

Clinical signs and symptoms of temporomandibular joint pain dysfunction syndrome were low ( $<20 \%)$, except for crepitus and click which affected between 24 and $40 \%$ of JIA children. Radiographically, $57 \%$ of oligoarticular and $77 \%$ of polyarticular cases exhibited condylar erosion. Use of systemic corticosteroids varied between centres, but overall, was prescribed more in polyarticular cases $(P=0.001)$.

Conclusions: Just under one-third of oligoarticular and polyarticular JIA patients exhibited a moderate or severe class II skeletal pattern. It is, therefore, likely that any future clinical trial to investigate the effect of functional appliance treatment in JIA patients, will need multicentre co-operation to fulfil potential sample size requirements. Clinical signs and symptoms of 
temporomandibular joint pain dysfunction syndrome were low except for crepitus and click. However, radiographic evidence of condylar erosion was high particularly in the polyarticular group. Use of systemic corticosteroids was prescribed more in polyarticular cases and this is likely to reflect the severity of the disease.

Key words: Juvenile idiopathic arthritis, class II skeletal pattern, temporomandibular joint signs and symptoms, corticosteroid treatment

Received 26th March 2009; accepted 9th October 2009

\section{Introduction}

Juvenile idiopathic arthritis (JIA) is a heterogeneous group of disorders with a common denominator of chronic synovitis of one or more joints. ${ }^{1,2}$ It occurs in $60-80$ per 100,000 children $^{3}$ and affects females to males in a ratio of $3: 2$. In the UK, the annual incidence is 10 per $100,000 .{ }^{4}$

Patients with JIA are all characterized by six weeks duration of arthritis with onset under the age of 16 years. ${ }^{5,6}$ The classification of juvenile arthritis has been the subject of much debate and change and the condition may manifest as different disease types but can be divided into two simple groups:

- mild disease defined as involving four or fewer joints at any point with minimal systemic manifestations (oligoarticular);

- more extensive disease involving five or more joints and often with systemic disease manifestations (polyarticular).

\section{Management of JIA}

A multidisciplinary team approach is required involving doctors, nurses, physiotherapists, psychologists and ophthalmologists. The primary aim of treatment is to avoid joint damage and there has been a trend in the recent decade to an earlier more aggressive approach with tight disease control. This is based on evidence that JIA is not a benign disease, joint damage occurs early and there is a recognized window of opportunity to preserve joint function and vision. ${ }^{2}$

However, medical management depends upon the type of JIA: if the child presents with oligoarthritis, they are treated with non-steroidal anti-inflammatory treatments and intra-articular corticosteroid injections. Polyarticular JIA is invariably treated more aggressively with methotrexate (oral or subcutaneous) and intra-articular and intravenous steroids (methylprednisolone). ${ }^{7}$

There has also been a temporal change, 15 years ago, towards the use of methotrexate, either in combination with corticosteroids, or alone and increasing use of biologic agents such as synthetic anti-TNF therapies.
The efficacy of methotrexate has been evaluated ${ }^{8-12}$ and is now the first line disease modifying anti-rheumatic drug used in paediatric rheumatology. A good response to methotrexate allows tapering and, in many cases, cessation of corticosteroids. In addition, a short interval from onset of disease to starting methotrexate treatment is an important predictor in reducing joint damage. ${ }^{13}$

\section{JIA, growth and temporomandibular joint (TMJ) involvement}

In addition, to considerable pain, discomfort and systemic effects of JIA, the disease has an effect on the growing skeleton. Growth and bone mass are reduced by persistent inflammation, and this is further exacerbated by immobility and corticosteroid use. In addition, local growth disturbances may occur. The most relevant of these problems for orthodontists is the effect of JIA on the facial skeleton and previous studies have suggested that JIA may influence mandibular growth. For example, an analysis of retrospective data reported that $40 \%$ of JIA children presented with class II malocclusion. ${ }^{14}$ Generally, this is because in JIA patients with TMJ involvement, changes in maxillary growth are relatively insignificant and the following mandibular growth changes are common: ${ }^{15-19}$

- smaller, retrognathic mandible;

- steep mandibular plane and decreased posterior facial height;

- increased gonial angle and more pronounced antegonial notching;

- proclination of the lower incisors.

It has therefore been suggested that preventing growth disturbance is also important in relation to facial growth since JIA children without TMJ involvement are more similar, craniofacially, to normal children. ${ }^{20}$ Reports of the percentage of JIA children with TMJ arthritis vary between 29 and $72 \%{ }^{21-26}$ and it is acknowledged that TMJ involvement is common and may be sub-clinical.

In particular, TMJ lesions seem to be associated with a number of disease factors such as early onset, long 
duration, polyarticular type with TMJ involvement particularly in boys ${ }^{26}$ high disease activity and importantly longstanding corticosteroid therapy. ${ }^{16,24,27-29}$

In contrast with the work of Kjellberg et al. ${ }^{20}$ it has been found that JIA children without clinical TMJ involvement also have mandibular deficiency when compared with healthy children. ${ }^{30}$ The general disease process and medication have been suggested as reasons for this. In other words, patients may still have low grade arthritis affecting the TMJ that is sub-clinical. As a result, interference with mandibular growth may be a combination of effects of restricted function, direct effects on the TMJ, or prolonged corticosteroid therapy.

The aim of this study was to screen patients with oligoarticular and polyarticular forms of JIA to determine:

(i) the severity of their class II skeletal pattern;

(ii) the prevalence of signs and symptoms of temporomandibular joint disorders;

(iii) the frequency of systemic corticosteroids use.

The rationale for the screening process was to determine whether the severity of class II skeletal pattern would support a future randomized clinical trial evaluating the effect of functional appliance treatment in patients with JIA.

\section{Subjects and method}

Consecutive 9-16-year-old JIA patients were recruited from Paediatric Rheumatology out-patient clinics in four centres: Manchester $(n=8)$, Liverpool $(n=31)$, Glasgow $(n=18)$ and Newcastle $(n=11)$. Patients were divided into two main groups: oligoarticular and polyarticular. The following exclusion criteria were applied:

- JIA subtypes other than oligoarticular or polyarticular;

- cleft lip and/or palate;

- non-caucasian patients;

- lack of written consent.

Ethical approval was obtained from Local Research Ethical Committees (LREC) for Manchester (01186), Liverpool (01/19/RE), Newcastle (2001/302) and Glasgow (P63/01). Informed written consent was obtained from the patient and a parent or guardian.

Patients were recruited from consecutive out-patient paediatric rheumatology clinics over a six to twelve month period. These out-patient clinics were attended weekly by one of the orthodontists involved in the study. It was believed likely that all possible JIA patients would attend for an appointment within this time period. Each patient was screened by the orthodontists, or information obtained from the notes by the paediatric rheumatologists, to record the following data:
- age, gender and length of time since JIA diagnosis;

- JIA sub-type;

- use of systemic corticosteroids (previous or current);

- clinical articulatory system in including a TMJ examination;

- overjet (upper incisor prominence measured from the lower incisors) (mm)

- lateral cephalogram;

- open mouth dental panoramic tomogram to show the right and left TMJ.

\section{Articulatory system (including TMJ) examination training}

Clinicians involved in data collection (NM, CRM, DM, AG, SW) received a day of training for examination of the articulatory system including the TMJ from RG. This included lectures and supervised clinical examination of 12 patients. The standardized examination is summarized in Table 1.

\section{Radiographic examination}

The lateral cephalograms were digitized twice by a single operator (KO'B) who had previously been shown to have high tracing reliability ${ }^{31}$ and average values calculated. Two outcome measures were used for antero-posterior skeletal discrepancy: difference in unit length between the maxilla and mandible and ANB. Maxillary unit length was measured in millimetres ( $\mathrm{mm}$ ) from the TMJ (posterior wall of the glenoid fossa) to lower ANS (defined as the point on the lower shadow of the anterior nasal spine where the projecting spine is $3 \mathrm{~mm}$ thick). Mandibular unit length was measured in $\mathrm{mm}$ from the TMJ (definition as above) to prognathion (the point on the bony chin contour giving the maximum length from the TMJ). These lateral cephalogram linear values were adjusted for magnification to allow the data from different centres to be combined.

The presence or absence of TMJ radiographic changes such as loss of condylar outline, erosion, osteophyte or sclerosis was determined by a TMD specialist (RG) from the open mouth orthopantomogram (OPT). Both radiographic examiners were blind to all patient details.

\section{Statistics}

Simple summary statistics were produced and the sample divided into the two main groups for analysis: mild disease defined as involving four or fewer joints at any point with minimal systemic manifestations (oligoarticular) and more extensive disease involving five or 
more joints and often with systemic disease manifestations (polyarticular). The difference in corticosteroid use between the JIA sub groups was examined using a Pearson's chi-square test.

\section{Results}

A total of 68 children were included in the study with 21 $(30.9 \%)$ males and 47 females $(69.1 \%)$. There were 33 patients in the oligoarticular group (48.5\%) and 35 in the polyarticular group $(51.5 \%)$. The mean age at examination was 12.8 years $(\mathrm{SD}=3.8$ years) in the oligoarticular group and 12.7 years $(\mathrm{SD}=2.5)$ in the polyarticular group. The mean time since diagnosis with JIA was 5.3 years $(\mathrm{SD}=4.6)$ in the oligoarticular group and 5.4 years $(\mathrm{SD}=3.1)$ in the polyarticular group.

Previous or current use of systemic corticosteroids is shown in Tables 2 and 3. Use of systemic corticosteroids varied between centres, but overall, was prescribed more in polyarticular cases (chi-squared $P=0.001$ ). and this is likely to reflect the severity of the disease

Descriptive statistics for the clinical and radiographic articulatory system examination are shown in Tables 4 and 5. Generally, clinical TMJ signs and symptoms were low $(<20 \%)$ except for crepitus or click which affected between 24 and $40 \%$ of children. Radiographically, just fewer than half the condyles examined had erosion, but virtually no children exhibited sclerosis or osteophyte formation.

A summary of the basic cephalometric data is shown in Tables 6 and 7. A class II skeletal pattern was defined as an ANB angle of $>4$ degrees. Around one quarter of patients in both the oligoarticular and polyarticular groups exhibited a mild class II skeletal pattern (ANB of
4.1-6 degrees) and just under one-third had a moderate or severe class II skeletal pattern (ANB $>6$ degrees). The data represent 55 patients, as 13 children either refused radiographs or were physically unable to walk to the X-ray department. Although these children could not have radiographs, no patients refused to participate in the study to receive a clinical examination.

\section{Discussion}

Overall, in this study, just under one-third of JIA patients, in either the oligoarticular or polyarticular group, had a moderate or severe class II skeletal pattern (ANB $>6$ degrees) and a further quarter of patients had a mild class II skeletal pattern (ANB 4.1-6 degrees) (Table 7). When these data are combined, around 50\% of JIA children screened had a class II skeletal pattern. Clinical signs and symptoms of TMJ pain dysfunction syndrome were low, except crepitus and clicking (24$40 \%$ ). A significant amount of condylar erosion was detected radiographically. Use of systemic corticosteroids varied between centres but, overall, was prescribed more in polyarticular cases, which is likely to reflect the severity of the disease.

\section{Strengths and weaknesses of the study}

The data from the screening give us valuable baseline information about the prevalence of class II skeletal pattern, TMJ signs and symptoms and radiographic changes to the condyles in UK children with JIA, since most of the previous literature has studied European samples. Data were collected on two distinct sub-types of JIA (oligoarticular and polyarticular); therefore,

Table 1 Standardized articulatory system examination for JIA screening

\begin{tabular}{lll}
\hline Examination & \multicolumn{1}{c}{ Lateral } & Method \\
TMJ pain & Intra-auricular & Palpation \\
Click & Stethoscope \\
$\begin{array}{l}\text { Crepitus } \\
\text { Joint swelling }\end{array}$ & Visual \\
$\begin{array}{l}\text { Pathway of opening } \\
\text { Locking }\end{array}$ & History \\
$\begin{array}{l}\text { Loss of movement } \\
\text { Muscle tenderness (temporalis, masseter, lateral pterygoid) }\end{array}$ & Palpation or mandibular movement against resistance \\
Mouth opening (maximum and lateral) & Vernier scale to nearest mm* (maximum opening \\
& measured between fully erupted upper and lower \\
\end{tabular}

\footnotetext{
*Alma bite gauge (Astek Ltd).
} 
removing the potential confounding effect of including many other JIA subtypes containing smaller numbers of patients. The disadvantage of the study was that a control group was not recruited; however, our primary aim was to carry out a screening study to assess the prevalence of class II skeletal pattern in JIA children.

Table 2 Use of systemic corticosteroids in oligoarticular and polyarticular JIA by centre

\begin{tabular}{llc}
\hline Received systemic corticosteroids $n(\%)$ by centre* & Oligoarticular $(n=33)$ & Polyarticular $(n=35)$ \\
\hline Manchester & & $2(40.0)$ \\
Yes & $0(0.0)$ & $3(60.0)$ \\
No & $3(100.0)$ & $3(60.0)$ \\
Newcastle & $1(25.0)$ & $2(40.0)$ \\
Yes & $3(75.0)$ & $10(66.7)$ \\
No & & $5(33.3)$ \\
Liverpool & $3(20.0)$ & $2(28.6)$ \\
Yes & $12(80.0)$ & $5(71.4)$ \\
No & $0(0.0)$ & $9(100.0)$ \\
Glasgow & & \\
Yes & & \\
No & & \\
\hline
\end{tabular}

$*_{n}=2$ missing data: oligoarticular group and $n=3$ missing data: polyarticular group.

Table 3 Use of systemic corticosteroids in oligoarticular and polyarticular JIA

\begin{tabular}{lll}
\hline Received systemic corticosteroids $n(\%)$ & Oligoarticular & Polyarticular \\
\hline Yes & $4(12.9)$ & $17(53.1)$ \\
No & $27(87.1)$ & $15(46.9)$ \\
\hline
\end{tabular}

Pearson chi-square value $11.46,1 \mathrm{df}, P=0.001$.

$*_{n}=2$ missing data: oligoarticular group and $n=3$ missing data: polyarticular group.

Table 4 Distribution by clinical symptoms of TMD according to subtype: oligoarticular and polyarticular JIA

\begin{tabular}{lll}
\hline & $n(\%)$ & \\
\cline { 2 - 3 } Presence of factor (left and/or right) & Oligoarticular $(n=33)$ & Polyarticular $(n=35)$ \\
\hline Lateral pain & $5(15.2)$ & $2(5.7)$ \\
Swelling & $0(0.0)$ & $1(2.9)$ \\
Intra-auricular pain & $5(15.2)$ & $2(5.7)$ \\
Crepitus & $13(39.4)$ & $13(37.1)$ \\
Click & $8(24.2)$ & $9(25.7)$ \\
Lock & $4(12.1)$ & $4(11.4)$ \\
TMJ - LOM & $3(9.1)$ & $4(11.8)$ \\
Missing & $\ldots$ & 1 \\
Muscle tenderness - temporalis & $1(3.0)$ & $5(14.7)$ \\
Missing & $\ldots$ & 1 \\
Muscle tenderness - masseter & $2(6.1)$ & $4(11.8)$ \\
Missing & $\ldots$ & 1 \\
Muscle tenderness - lateral pterygoid & $4(12.1)$ & $3(8.6)$ \\
Maximum opening (mm) Mean (SD) & $35.8(8.6)$ & $34.4(9.1)$ \\
Lateral movement (mm) Mean (SD) & $7.7(3.1)$ & $7.5(2.6)$ \\
\hline
\end{tabular}




\section{Comparison with previous literature}

\section{Class II cephalometric data for JIA patients}

Our screening study found a $50 \%$ prevalence of a class II skeletal pattern in children with JIA, whereas Kjellberg et al. ${ }^{14}$ reported a $40 \%$ prevalence of class II malocclusion; however the data are not directly comparable. The latter authors ${ }^{14}$ reported the presence of Angle's class II malocclusion, which may not reflect an underlying class II skeletal pattern.

It is possible that this screening study underestimated the severity of class II skeletal pattern in JIA children, because 13 children either refused radiographs or were unable to walk to the X-ray department. This could have biased the results towards the less sick children, who may also have had a less severe class II skeletal pattern. In retrospect, it would have been advisable to offer transport, within the hospital, for more severely physically affected patients, so their cephalometric data could have been collected.

Comparison of cephalometric data with previous literature is made in Table 8. This UK JIA sample did not exhibit a steep mandibular plane angle or proclination of the lower incisors noted in other cephalometric studies. ${ }^{15-19,32}$ The more severe ANB values reported in European studies may be partly explained by selection of patients with clinical micrognathia or more severe abnormalities of the TMJ, rather than screening every patient with JIA. Alternatively, a move towards the use of early treatment with disease modifying anti-rheumatic drugs in the mid 1980s could mean that patients treated since then have less severe disease. The eldest patient in this study was 16 years of age, so it is likely that all patients screened, started treatment for JIA after the mid 1980s. It might be hypothesized that a less severe general disease process might result in less TMJ damage and a less severe class II skeletal pattern, compared with older data collected before changes in management of the disease.

\section{Clinical and radiographic TMD findings}

When clinical TMD signs or symptoms are considered, crepitus and restricted mouth opening have been reported as the main problems ${ }^{28,33}$ and this is in broad agreement with the findings in this study.

Table 5 Distribution by radiographic signs of TMD according to subtype: oligoarticular and polyarticular JIA

\begin{tabular}{lll}
\hline & $n(\%)$ & \\
\cline { 2 - 3 } Presence of factor (left and/or right) & Oligoarticular $(n=33)$ & Polyarticular $(n=35)$ \\
\hline Condylar erosion & $16(57.1)$ & $20(76.9)$ \\
Missing/unreadable & 5 & 9 \\
Sclerosis & $1(3.7)$ & $0(0.0)$ \\
Missing/unreadable & 6 & 10 \\
Osteophyte & $1(3.7)$ & $0(0.0)$ \\
Missing/unreadable & 6 & 11 \\
\hline
\end{tabular}

Table 6 Descriptive cephalometrics for JIA patients with oligoarticular and polyarticular disease groups

\begin{tabular}{lll}
\hline & \multicolumn{1}{c}{ Mean $(\mathrm{SD})$ (degrees or mm) } & \\
\cline { 2 - 3 } Cephalometric variable & Oligoarticular $(n=33)$ & Polyarticular $(n=35)$ \\
\hline SNA & $80.9(2.9)$ & $79.9(2.7)$ \\
SNB & $76.7(4.1)$ & $74.9(4.3)$ \\
ANB & $4.2(2.9)$ & $5.1(3.8)$ \\
Maxillary unit length & $81.8(6.3)$ & $78.8(8.0)$ \\
Mandibular unit length & $103.5(9.6)$ & $99.9(11.7)$ \\
Max/Mand unit difference & $21.8(6.3)$ & $21.1(5.8)$ \\
Maxillo-mandibular planes angle & $28.9(7.2)$ & $31.3(7.5)$ \\
\%Lower face height & $54.4(2.2)$ & $54.1(2.0)$ \\
Upper incisor/maxillary plane & $107.3(7.4)$ & $110.3(6.7)$ \\
Lower incisor/mandibular plane & $95.6(8.0)$ & $93.9(8.9)$ \\
Interincisal angle & $130.4(11.2)$ & $125.8(14.2)$ \\
Overjet & $2.7(2.1)$ & $3.9(3.0)$ \\
Missing & 5 & 8 \\
\hline
\end{tabular}


Table 7 Class II skeletal pattern in JIA patients

\begin{tabular}{lll}
\hline & $n(\%)$ & \\
\cline { 2 - 3 } ANB (degrees) & Oligoarticular $(n=33)$ & Polyarticular $(n=35)$ \\
\hline$<2$ & $5(17.9)$ & $4(14.8)$ \\
$2-4$ & $9(32.1)$ & $8(29.6)$ \\
$4.1-6$ & $6(21.4)$ & $7(25.9)$ \\
$>6$ & $8(28.6)$ & $8(29.6)$ \\
Missing & 5 & 8 \\
\hline
\end{tabular}

Around one-third of this sample had crepitus and previous reports have ranged from 15 to $55 \%{ }^{25,28,34}$ Ronchezel (1995) ${ }^{35}$ reports combination crepitus in $71 \%$ of polyarticular and $42 \%$ of pauciarticular patients, but since this is combined with the presence of TMJ pain, it cannot be compared with the data from this study.

The amount of mouth opening can only be cautiously compared with previous literature because of wide age ranges and possible differences in measurement methods. Mean maximum mouth opening for this sample was around $35 \mathrm{~mm}$ with previous authors reporting values of $29.2 \mathrm{~mm},{ }^{16} 49.5 \mathrm{~mm}^{34}$ and a range of $23-36 \mathrm{~mm} .{ }^{28}$

Temporalis tenderness and palpation tenderness of the posterior aspect of the TMJ (intra-auricular) were lower in this study than reported by Forsberg et al. $(1988)^{34}$ (3\% for oligoarticular and $14.7 \%$ for polyarticular compared with Forsberg's $40 \%$ for temporalis tenderness). These differences could possibly be explained by the cross-sectional nature of temporomandibular joint examinations and that the severity of signs and symptoms may come and go.

We detected radiographic signs of condylar erosion in between 57 and $77 \%$ of JIA children and previous reports suggest radiographic lesions are present in $29-72 \%$ of cases. Again, direct comparison with previous literature should be made with care because of different recording and imaging methods. ${ }^{21,23-27,32,35}$ Interestingly, at long term 17 years follow-up $(n=9),{ }^{28}$ Larheim, Haanaes and Ruud reported severe arthritic destruction in all of their JIA patients which suggests that cross-sectional studies of younger children may under-estimate arthritic damage to the TMJ. Such under-estimates may be further compounded by the relative lack of sensitivity of clinical and

Table 8 Comparison of JIA cephalometric values with previous literature

\begin{tabular}{|c|c|c|c|c|c|c|c|c|}
\hline Author/date & SNA & $\mathrm{SNB}$ or $\mathrm{SN} / \mathrm{Po}$ & ANB & MMPA & $\% \mathrm{LFH}$ & $\begin{array}{l}\text { Upper Inc/Max } \\
\text { plane or nasal plane* }\end{array}$ & $\begin{array}{l}\text { Lower Inc/ } \\
\text { Mand plane }\end{array}$ & $\begin{array}{l}\text { Inter-incisal } \\
\text { angle }\end{array}$ \\
\hline $\begin{array}{l}\text { Barriga }(1974)^{37} \\
n=27, \text { age } 3-18 \text { years } \\
\text { Washington, USA sample }\end{array}$ & 82.0 & 75.7 & 6.7 & & & & & \\
\hline $\begin{array}{l}\text { Larheim and Haanaes }(1981)^{27} \\
\text { Oslo sample } \\
n=20, \text { age } 15-35 \text { years } \\
\text { Jamsa and Ronning }(1985)^{38} \\
\text { Helsinki sample } \\
n=28, \text { mean age } 15.5 \text { years }\end{array}$ & 80.3 & 69.2 & 11.1 & & & & & 118.0 \\
\hline Boys & 82.5 & 73.0 & & & & 108.5 & 94.0 & 117.0 \\
\hline Girls & 82.5 & 71.5 & & & & 116.5 & 90.0 & 111.0 \\
\hline $\begin{array}{l}\text { Stabrun }(1991)^{18} \\
\text { Oslo sample } \\
n=26, \text { mean age } 14.7 \text { years } \\
\text { Ronning, Barnes, Pearson }(1994)^{19} \\
\text { Finnish sample } \\
n=\text { between } 6 \text { and } 12 \text { in each age grou }\end{array}$ & 81.6 & 75.0 & 6.7 & & & & 103.6 & 118.2 \\
\hline $8-10$ years & 80.7 & 75.5 & 5.8 & 34.3 & 60.5 & 107.9 & 97.9 & 121.2 \\
\hline $11-13$ years & 80.7 & 73.9 & 6.3 & 38.8 & 52.2 & 109.7 & 95.2 & 118.4 \\
\hline $14-16$ years & 80.2 & 73.6 & 6.7 & 40.1 & 60.7 & 109.0 & 94.1 & 117.4 \\
\hline $\begin{array}{l}\text { Hu, Billiau, Verdonck et al. }(2009)^{32} \\
\text { (Median values) } \\
\text { Belgian sample } \\
n=100 \text {, JIA age range } 1.7-19.4 \text { years } \\
\text { This study: } n=55\end{array}$ & 83.0 & 78.3 & 4.3 & 36.8 & 54.1 & & & 121.5 \\
\hline Oligoarticular 12.8 years & 80.9 & 76.7 & 4.2 & 28.9 & 54.4 & 107.3 & 95.6 & 130.4 \\
\hline Polyarticular 12.7 years & 79.9 & 74.9 & 5.1 & 31.3 & 54.1 & 110.3 & 93.9 & 125.8 \\
\hline
\end{tabular}


radiographic TMJ examination, compared with enhanced magnetic resonance imaging. ${ }^{36}$

\section{JIA and systemic corticosteroid use}

Previous literature has suggested that longstanding systemic corticosteroid therapy may influence the extent of TMJ signs or symptoms. ${ }^{16,24,27-29}$ It has also been suggested that prolonged systemic corticosteroid treatment may influence the severity of the class II skeletal pattern, ${ }^{14}$ as corticosteroids have a general effect on growth that may extend to restriction of mandibular growth. The data from this study do not seem to support this, as corticosteroid use in polyarticular patients was higher than the oligoarticular group, but their cephalometric data were very similar. Although this extrapolation is beyond the scope of a screening study, it is a possible topic for future research.

\section{Implications for clinical practice: a clinical trial investigating the effect of functional appliance treatment in JIA children}

This screening study, in four UK centres, identified that just under one-third of children with JIA to have a moderate or severe class II skeletal pattern (combined oligoarticular and polyarticular cases $n=16$ with ANB $>6$ degrees). In a previous study, ${ }^{31}$ a sample size of 80 patients per study group was collected from 14 centres to compare two types of functional appliance. Therefore, national, multi-centre co-operation would be needed to recruit enough JIA children suitable for functional appliance treatment in a clinical trial.

\section{Conclusions}

- Just under one-third of patients with oligoarticular and polyarticular JIA exhibited a moderate to severe class II skeletal pattern.

- The frequency of clinical signs and symptoms of temporomandibular joint pain dysfunction syndrome were also low, except for crepitus and clicking; however, radiographic evidence of condylar erosion was high particularly in the polyarticular group.

- The use of systemic corticosteroids varied between centres, but overall, was prescribed more in polyarticular cases, and this is likely to reflect the severity of the disease.

\section{Acknowledgement}

This study was funded by the British Orthodontic Society Fund (BOSF).

\section{Contributors}

Main authors:

$\mathrm{N}$ Mandall carried out the literature search and review, developed the protocol, obtained multi centre ethical approval, undertook data collection at Alder Hey Hospital, organised the TMD training day, undertook data entry, cleaning and writing of paper. E Baildam had the original idea and approved the protocol, undertook data collection at Booth Hall hospital. R Gray is a TMD specialist who organised and delivered training for all examiners and assessed OPT data. $T$ Macfarlane gave statistical advice and carried out the analysis. K O'Brien had the original idea, approved the protocol and carried out measurement of lateral cephalograms.

Co-authors:

J Davidson, H Foster, J Gardner-Medwin, J Sills: Paediatric Rhematologists allowed unrestricted access to their clinics for between 6-12 months, data extraction from notes.

T Walsh: gave statistical advice

A Garrahy, CR Mattick, D Millett, S Ward: clinicians collected data on rheumatology clinics including clinical TMJ examination, completion of data proformas, request and collection of radiographs, weekly clinic attendance for 6 months.

$\mathrm{N}$ Mandall is the guarantor

\section{References}

1. Brewer EJ, Bass JC, Baum JT et al. Current proposed revision of JRA criteria. Arthritis Rheum 1977; 20: 195-99.

2. Ravelli A, Martini A. Juvenile idiopathic arthritis. Lancet 2007; 369: 767-78.

3. Andersson Gare B, Fasth A. Epidemiology of juvenile chronic arthritis in Southwestern Sweden: a 5-year prospective population study. Pediatrics 1992; 90: 950-58.

4. Symmons DP, Jones M, Osborne J, Sills J, Southwood TR, Woo P. Pediatric rheumatology in the United Kingdom: data from the British Pediatric Rheumatology Group National Diagnostic Register. J Rheumatol 1996; 23: 1975-80.

5. Petty RE, Southwood TR, Baum J. Revision of the proposed classification criteria for juvenile idiopathic arthritis: Durban 1997. J Rheumatol 1998; 25: 1991-94.

6. Petty RE, Southwood TR, Manners P. International League of Associations for rheumatology classification of juvenile idiopathic arthritis. Second revision: Edmonton 2001. J Rheumatol 2004; 31: 390-92.

7. Wallace CA. The use of methotrexate in childhood rheumatic diseases. Arthritis Rheum 1998; 41: 381-89. 
8. Huang JL. Methotrexate in the treatment of children with chronic arthritis - long term observation of efficacy and safety. Br J Clin Pract 1996; 50: 311-14.

9. Ruperto N, Ravelli A, Falcini F et al. Performance of the preliminary definition of improvement in chronic arthritis patients treated with methotrexate. Italian Pediatric Rheumatology Study Group. Ann Rheum Dis 1998; 57: $38-41$.

10. Al-Sewairy W, Al-Mazyed A, Al-Dalaan S, Bahabri S. Methotrexate therapy in systemic onset juvenile rheumatoid arthritis in Saudi Arabia - a retrospective analysis. Clin Rheumatol 1998; 17: 52-57.

11. Ravelli A, Viola S, Ramenghi B, Beluffi G, Zonta LA, Martini A. Radiographic progression in patients with juvenile chronic arthritis treated with methotrexate. J Pediatr 1998; 133: 262-65.

12. Shetty AK, Zganjar BE, Ellis GS, Ludwig IH, Gedalia A. Low dose methotrexate in the treatment of severe juvenile rheumatoid arthritis and sacrcoid iritis. $J$ Pediatr Ophthalmol Strabismus 1999; 36: 125-28.

13. Ravelli A, Martini A. Early predictors of outcome in juvenile idiopathic arthritis. Clin Rheumatol 2003; 21: 489-93.

14. Kjellberg H, Fasth A, Kiliaridis S, Wenneberg B, Thilander B. Craniofacial structure in children with juvenile chronic arthritis (JCA) compared with healthy children with ideal or post normal occlusion. Am J Orthod Dentofacial Orthop 1995; 107: 67-78.

15. Odenrick L. Potential micrognathia in children with juvenile rheumatoid arthritis. Trans Eur Orthod Soc 1977; 53: 207-16.

16. Larheim TA, Haanaes HR. Micrognathia, temporomandibular joint changes and dental occlusion in juvenile rheumatoid arthritis of adolescents and adults. Scand $J$ Dent Res 1981; 89: 329-38.

17. Bjork A, Skieller V. Contrasting mandibular growth and facial development in long face syndrome juvenile rheumatoid polyarthritis and mandibulofacial dysostosis. J Craniofac Genet Dev Biol 1985; Suppl 1: 127-38.

18. Stabrun AE. Impaired mandibular growth and micrognathic development in children with juvenile rheumatoid arthritis. A longitudinal study of lateral cephalographs. Eur J Orthod 1991; 13: 423-34.

19. Ronning O, Barnes SAR, Pearson MH, Pledger DM. Juvenile chronic arthritis: a cephalometric study of the facial skeleton. Eur J Orthod 1994; 16: 53-62.

20. Kjellberg H, Kiliaridis S, Thilander B. Dentofacial growth in orthodontically treated and untreated children with juvenile chronic arthritis (JCA). A comparison with Angle class II division I subjects. Eur J Orthod 1995; 17: 357-73.

21. Ronning O, Valiaho ML, Laaksonen AL. The involvement of the temporomandibular joint in juvenile rheumatoid arthritis. Scand J Rheumatol 1974; 3: 347-53.

22. Ronning $\mathrm{O}$, Valiaho ML. Involvement of the facial skeleton in juvenile rheumatoid arthritis. Ann Radiol (Paris) 1975; 43: 347-53.
23. Ronning O, Valiaho ML. Progress of mandibular condyle lesions in juvenile rheumatoid arthritis. Proc Finn Dent Soc 1981; 77: 151-57.

24. Larheim TA, Hoyeraal HM, Stabrun AE, Haanaes HR. The temporomandibular joint in juvenile rheumatoid arthritis. Scand JRheumatol 1982; 11: 5-12.

25. Olsen L, Eckerdal O, Hallonsten AL, Helkimo M, Koch G, Andersson Gare B. Craniomandibular function in juvenile chronic arthritis. A clinical and radiographic study. Swed Dent $J$ 1991; 15: 71-83.

26. Karhulahti T, Ylijoki H, Ronnong O. Mandibular condyle lesions related to onset and subtypes of juvenile rheumatoid arthritis in 15 year old children. Scand J Dent Res 1993; 101: 332-38.

27. Larheim TA, Haanaes HR, Dale K. Radiographic temporomandibular joint abnormality in adults with micrognathia and juvenile rheumatoid arthritis. Acta Radiog (Diagn) 1981; 22: 495-504.

28. Larheim TA, Haanaes HR, Ruud AF. Mandibular growth, temporomandibular joint changes and dental occlusion in juvenile rheumatoid arthritis. Scand J Rheumatol 1981; 10: 225-33.

29. Stabrun A, Larheim TA, Hoyeraal HM, Rosler M. Reduced mandibular dimensions and asymmetry in juvenile rheumatoid arthritis. Pathogenetic factors. Arthritis Rheum 1988; 31: 602-11.

30. Stabrun AE. Mandibular morphology and position in juvenile rheumatoid arthritis. A study on postero-anterior radiographs. Eur J Orthod 1985; 7: 288-98.

31. O'Brien K, Wright J, Conboy F et al. Effectiveness of early orthodontic treatment with the Twin-block appliance: A multicenter, randomized controlled trial. Part 1: dental and skeletal effects. Am J Orthod Dentofacial Orthop 2003; 124: 234-43.

32. Hu Y, Billiau An D, Verdonck An, Wouters C, Carels C. Variation in dentofacial morphology and occlusion in juvenile idiopathic arthritis subjects: a case control study. Eur J Orthod 2009; 31: 51-58.

33. Billiau An D, Hu Y, Verdonck An, Carels C, Wouters C. Temporomandibular joint arthritis in juvenile idiopathic arthritis: Prevalence, clinical and radiological signs, and relation to dentofacial morphology. J Rheumatol 2007; 34: 1925-33.

34. Forsberg M, Agerberg G, Persson M. Mandibular dysfunction in patients with juvenile rheumatoid arthritis. J Craniomandib Disord 1988; 2: 201-08.

35. Ronchezel MV, Odete M, Goldenberg HJ et al. Temporomandibular joint and mandibular growth alterations in patients with juvenile rheumatoid arthritis. J Rheumatol 1995; 22: 1956-61.

36. Kuseler A, Pederson TJ, Herlin T, Gelineck J. Contrast enhanced magnetic resonance imaging as a method to diagnose early inflammatory changes in the temporomandibular joint in children with juvenile chronic arthritis. J Rheumatol 1998; 25: 1406-12. 
37. Barriga B, Lewis TM, Law DB. An investigation of the dental occlusion in children with juvenile rheumatoid arthritis. Angle Orthod 1974; 44: 329-35.
38. Jamsa $\mathrm{T}$, Ronning $\mathrm{O}$. The facial skeleton in children affected by rheumatoid arthritis - a roentgen - cephalometric study. Eur J Orthod 1985; 7: 48-56. 